\title{
A cancer genetics toolkit improves access to genetic services through documentation and use of the family history by primary-care clinicians
}

\author{
Maren T. Scheuner, MD, MPH ${ }^{1,2}$, Alison B. Hamilton, PhD, $\mathrm{MPH}^{1,3}$, Jane Peredo, $\mathrm{MS}^{1}$, \\ Taylor J. Sale, MS, MED ${ }^{1}$, Colletta Austin, RN, MSN ${ }^{1}$, Stuart C. Gilman, MD, MPH ${ }^{4}$, \\ M. Scott Bowen, MPH ${ }^{5}$, Caroline Lubick Goldzweig, MD, MSPH ${ }^{1,2}$, Martin Lee, $\mathrm{PhD}^{1,6}$, \\ Brian S. Mittman, $\mathrm{PhD}^{1}$ and Elizabeth M. Yano, PhD, MSPH ${ }^{1,6}$
}

Purpose: We developed, implemented, and evaluated a multicomponent cancer genetics toolkit designed to improve recognition and appropriate referral of individuals at risk for hereditary cancer syndromes.

Methods: We evaluated toolkit implementation in the women's clinics at a large Veterans Administration medical center using mixed methods, including pre-post semistructured interviews, clinician surveys, and chart reviews, and during implementation, monthly tracking of genetic consultation requests and use of a reminder in the electronic health record. We randomly sampled $10 \%$ of progress notes 6 months before $(n=139)$ and 18 months during implementation $(n=677)$.

Results: The toolkit increased cancer family history documentation by almost $10 \%$ (26.6\% pre- and $36.3 \%$ postimplementation). The

\section{INTRODUCTION}

Hereditary breast-ovarian cancer (HBOC) and Lynch syndrome are relatively common hereditary cancer syndromes associated with high risks and early onset for breast, ovarian, colon, endometrial, and other cancers, ${ }^{1,2}$ necessitating more intensive screening ${ }^{1-4}$ and prevention options..$^{5-11}$ Documenting family history is important for recognizing individuals who may have a predisposition to HBOC or Lynch syndrome, particularly individuals without a personal history of cancer who may have the most to gain from genetic risk assessment and resulting recommendations for risk-appropriate cancer screening and prevention. In addition, genetic testing can refine the genetic risk in high-risk families and further inform recommendations for screening and prevention, particularly when a familial mutation is known. ${ }^{1,2,12,13}$

Genetic testing for HBOC or Lynch syndrome in an unaffected individual may be useful without knowing of a familial mutation when there is a compelling family history, and when the results will provide additional cancer risk information resulting in a change in screening and prevention recommendations. For example, BRCA1/2 gene testing would be indicated for an reminder was a key component of the toolkit; when used, it was associated with a twofold increase in cancer family history documentation (odds ratio $=2.09 ; 95 \%$ confidence interval: $1.39-3.15$ ), and the history was more complete. Patients whose clinicians completed the reminder were twice as likely to be referred for genetic consultation $(4.1-9.6 \%, P<0.0001)$.

Conclusion: A multicomponent approach to the systematic collection and use of family history by primary-care clinicians increased access to genetic services.

Genet Med advance online publication 13 June 2013

Key Words: family history; hereditary cancer; referral

unaffected woman with multiple, close family members with early-onset breast cancer, ${ }^{12}$ because identifying a mutation would confirm a high risk for breast cancer and ovarian cancer, and risk-reducing bilateral salpingo-oophorectomies would be recommended after child-bearing is complete. ${ }^{1,12}$ If a BRCA1/2 gene mutation were not identified, then her personal and family history risk factors would inform her risk assessment and options for cancer screening and prevention, and without a family history of ovarian cancer, there would be no strong indication for risk-reducing bilateral salpingo-oophorectomy. ${ }^{1}$ Similarly, germline testing for a mismatch repair gene mutation associated with Lynch syndrome (i.e., MSH2, MLH1, MSH6, and PMS2) could inform important cancer risks for an unaffected woman with multiple, close family members with early-onset colon cancer. If a mutation were identified, then in addition to a high risk for colon cancer, high risks for endometrial and ovarian cancer would be confirmed, and risk-reducing hysterectomy and bilateral salpingo-oophorectomy should be considered after child-bearing is complete. ${ }^{2}$ If no mismatch repair gene mutation were found, then cancer surveillance and prevention would rely on her personal and familial risks; ${ }^{2}$ without a family history of endometrial

${ }^{1}$ VA Greater Los Angeles Healthcare System, Los Angeles, California, USA; ${ }^{2}$ Department of Medicine, David Geffen School of Medicine at UCLA, Los Angeles, California, USA; ${ }^{3}$ Department of Psychiatry and Biobehavioral Sciences, David Geffen School of Medicine at UCLA, Los Angeles, California, USA; ${ }^{4}$ Office of Academic Affiliations, Veterans Health Administration, Washington, DC, USA; ${ }^{5}$ Office of Public Health Genomics, Centers for Disease Control and Prevention, Atlanta, Georgia, USA; ${ }^{6} \mathrm{UCLA}$ Fielding School of Public Health, Los Angeles, California, USA. Correspondence: Maren T. Scheuner (maren.scheuner@va.gov) 
or ovarian cancer, there would be no indication for risk-reducing hysterectomy and bilateral salpingo-oophorectomy.

Thus, family history is important for accurate cancer risk assessment and clinical decision making. Unfortunately, family history is insufficiently documented and underutilized in clinical practice. In a national physician survey, a minority of primary-care providers recognized the family history patterns that were appropriate indications for HBOC testing. ${ }^{14}$ In an analysis of the 2005 National Health Interview Survey, half of the respondents in the highest familial risk groups for either HBOC or Lynch syndrome had heard of genetic testing; of those, only $15 \%$ had discussed it with their physician, and only $4.5 \%$ had received a genetic test. ${ }^{15}$ These surveys and other research ${ }^{16-20}$ suggest that clinician education about family history risk assessment is needed, along with increased awareness of existing genetic testing and referral guidelines. To address the need for clinician education and systems improvement, we developed an innovative multicomponent implementation strategy ${ }^{21}$ in the form of a cancer genetics toolkit designed to improve familial risk assessment and appropriate referrals for HBOC and Lynch syndrome. The toolkit components were grouped as informational, clinical, and behavioral, mirroring a definition of continued medical education interventions, ${ }^{22}$ because most experts agree that multifaceted interventions are preferable and necessary to change clinician behavior and improve patient outcomes. ${ }^{22-25} \mathrm{We}$ developed and evaluated the feasibility and effectiveness of this toolkit in the women's primary-care clinics at a large Veterans Administration (VA) medical center.

\section{MATERIALS AND METHODS}

\section{Study design}

We developed a cancer genetics toolkit and evaluated its impacts by comparing clinician behaviors relating to documentation of cancer family history and referral for genetic consultation before and after implementation. We used mixed methods, including semistructured interviews, chart review, tracking of referrals to clinical genetics, and tracking of a clinical decision support tool in the form of a clinical reminder in the electronic health record (EHR). The VA Greater Los Angeles Healthcare System (GLA) Institutional Review Board approved all study procedures.

\section{Intervention}

A description of the toolkit components and associated implementation activities is provided in Table 1. During the first year of this project, we developed our toolkit components with input from a multidisciplinary advisory committee composed of VA and non-VA experts in clinical genetics, genetic counseling, genetics education, oncology, health services, women's health, and ethics. Our advisory committee helped us to identify the key concepts important to cancer genetics education. We subsequently identified existing sources of information addressing these concepts from the literature and the Internet; these were incorporated into the informational components of our toolkit.

One of the clinical tools developed was a reminder for the EHR. A reminder alerts the clinician working within a patient record to take action; in this case, it was an alert to collect cancer family history followed by a decision about referral for genetic consultation. The clinician responses in the reminder were documented in the patient's progress note and captured as data elements by the database supporting the EHR. We went through multiple iterations of the reminder, with feedback from end users (primary-care clinicians) through discussion groups and usability testing. Once finalized, the integration of the reminder into the EHR at the VA GLA was straightforward. Maintenance of the reminder required minimal effort and only required attention when the EHR went through periodic updates.

The lecture series, patient and clinician information sheets, clinical reminder, and patient family history questionnaire are available on request.

\section{Setting and participants}

We implemented our toolkit within the women's clinics at GLA. These clinics provide primary care to women veterans at two locations, West Los Angeles and Sepulveda. ${ }^{26,27}$ GLA is one of the largest VA medical centers, with $>85,000$ outpatient visits each year. GLA serves veterans living in the geographic area within an approximate 100-mile range from its location in Los Angeles; this includes both urban and rural locations as well as diverse socioeconomic and racial/ethnic populations. It is one of the few VA facilities that has comprehensive clinical genetic services available on site. The availability of these onsite services preceded the toolkit implementation by 6 months, and prior to this, genetic consults were available to veterans through arrangements with specialists in the community. Yet, despite the availability of these services, there were no referrals to genetics in the year prior to implementation, suggesting lack of awareness, underutilization, and a need for education about cancer genetics and indications for referral. The toolkit was deployed among all staff clinicians and supervised trainees (i.e., medical students and physician residents) in the women's clinics. Only the staff clinicians were invited to participate in the semistructured interviews and needs assessment survey.

\section{Main outcome measures}

We assessed change in frequencies of cancer family history documentation in the EHR and referrals for genetic consultation for a 6-month period before (April through September 2009) and for 18 months during toolkit implementation (April 2010 through September 2011). We also assessed clinicians' knowledge and attitudes about cancer genetics and the individual tools in our toolkit.

\section{Needs assessment survey}

We developed a list of domains for our needs assessment survey through a combination of literature review and expert opinion, used standard survey development approaches to design survey content, and then performed cognitive testing of the resulting survey instrument (see Supplementary Data S1 online) with members of our advisory committee. The survey was administered before our toolkit was implemented and 
Table 1 The multicomponent cancer family history toolkit

Tool Description

Informational

component

Lecture series

Continuing medical education-approved lecture series. Seven lectures were delivered on the topics of risk assessment for hereditary cancer syndromes; genetic testing; hereditary breast-ovarian cancer; hereditary colon cancer; ethical, legal, and social issues; case studies; and a genetics "Jeopardy" game.

Patient information sheets

\section{One information sheet describes the} importance of knowing cancer family history. Another describes how patients should prepare for and what they should expect during a genetic consultation.

$\begin{array}{ll}\begin{array}{l}\text { Clinician } \\ \text { information } \\ \text { sheets }\end{array} & \begin{array}{l}\text { Checklist of indications for referral of a } \\ \text { patient for a cancer genetics consultation. }\end{array} \\ \begin{array}{l}\text { GCAT } \\ \text { Sharepoint site }\end{array} & \begin{array}{l}\text { Genomics Curriculum And Tools website } \\ \text { containing all informational tools and links } \\ \text { to trusted websites. }\end{array}\end{array}$

Clinical component

Clinical decision support tool in the form of a reminder

\section{An alert to clinicians working in the EHR} to collect cancer family history, followed by a decision about referral for genetic consultation. To respond to the alert and complete the reminder, the clinician answered eight structured questions regarding cancer family history with "yes," "no," and "don't know" responses, elaborating on the "yes" responses. Following cancer family history collection, the reminder asked the clinician to decide whether a genetic consultation was indicated by selecting (i) request genetic consult, (ii) patient declines genetic consult, or (iii) genetic consult not indicated. Links to information sheets, GCAT site, and other websites are available.

$\begin{array}{ll}\begin{array}{l}\text { Patient } \\ \text { questionnaire }\end{array} & \begin{array}{l}\text { Consists of questions that mirror the } \\ \text { questions asked in the reminder found } \\ \text { in the EHR. }\end{array}\end{array}$

Implementation activities

Geneticist conducted lectures every 2 to 3 weeks in the women's clinics during the first half of implementation.

\section{Clinician feedback}

The cancer family history information sheet was provided to patients when they

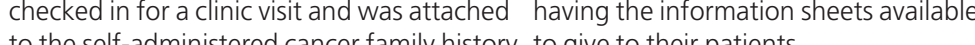
to the self-administered cancer family history to give to their patients. questionnaire, described below. The genetic consultation information sheet was given to clinicians, who then could share it with patients they referred.

Available in print and also embedded within a reminder in the electronic health record (EHR), described below.

Embedded within the EHR reminder, described below. and accessible. Clinicians appreciated

Helped provide context for use of family history and referral to genetics. Almost all clinicians expressed an interest in additional lectures including periodic updates on the same topics, as well as addressing new topics relevant to women's health, such as preconception/ prenatal testing.

Important to keep the sheets visible

(n)




\begin{tabular}{|c|c|c|c|}
\hline Tool & Description & Implementation activities & Clinician feedback \\
\hline \multicolumn{4}{|l|}{$\begin{array}{l}\text { Behavior-change } \\
\text { component }\end{array}$} \\
\hline $\begin{array}{l}\text { Practice-feedback } \\
\text { report }\end{array}$ & $\begin{array}{l}\text { Describes the proportion of patients with } \\
\text { a completed reminder and proportion } \\
\text { referred for genetic consultation, as } \\
\text { compared with an aggregate summary for } \\
\text { the clinic. }\end{array}$ & $\begin{array}{l}\text { Generated on a quarterly basis during } \\
\text { the implementation phase for individual } \\
\text { enrolled clinicians. }\end{array}$ & $\begin{array}{l}\text { Some reacted to the numbers in } \\
\text { their reports; others did not view their } \\
\text { reports, mostly because they were } \\
\text { not aware the reports were delivered } \\
\text { to them (hard copy via interoffice mail). } \\
\text { For those who looked at the report, } \\
\text { they generally appreciated seeing } \\
\text { how they were doing regarding } \\
\text { use of the reminder and referral to } \\
\text { genetics in comparison to their peers. }\end{array}$ \\
\hline Social influence & $\begin{array}{l}\text { Clinic champions are notified of missed } \\
\text { opportunities found by review of health } \\
\text { factors. Champions contact clinicians } \\
\text { regarding possible need for referral. }\end{array}$ & $\begin{array}{l}\text { Ongoing review of consults received } \\
\text { by the genetics team characterizes the } \\
\text { appropriateness of referrals. Real-time } \\
\text { individual clinician feedback is provided } \\
\text { and monthly reports are generated. }\end{array}$ & $\begin{array}{l}\text { Many clinicians appreciated the } \\
\text { feedback they received about cases } \\
\text { that perhaps could benefit from a } \\
\text { genetics referral; it ensured that their } \\
\text { patients "won't fall through the cracks." }\end{array}$ \\
\hline
\end{tabular}

The toolkit components were grouped as informational, clinical, and behavioral. The lecture series, patient and clinician information sheets, clinical reminder, and patient family history questionnaire are available upon request.

GCAT, Genomics Curriculum And Tools.

18 months after implementation to the staff clinicians. The survey assessed clinician knowledge of cancer genetics (31 multiple-choice items) and their attitudes about the relevance of cancer genetics to their practice (11 items with a four-point scale: 1 , not at all relevant; 2 , somewhat relevant; 3 , relevant; and 4 , very relevant). Knowledge and attitude questions addressed the following topics: genetic concepts and terminology, familial risk assessment, recognition of hereditary cancer syndromes, genetic testing, referral and management of individuals with hereditary cancer, and ethical issues for patients and clinicians.

\section{Semi-structured interviews}

We interviewed the staff clinicians in the women's clinics after 7 and 18 months of implementation to assess their attitudes and opinions regarding the toolkit and its implementation using a standardized protocol (see Supplementary Data S2 online). The same clinicians were interviewed at the two time points. Interviews were transcribed verbatim, and transcripts were reviewed and edited for accuracy and content. After careful review and discussion, a deductive, "top-down" coding scheme ${ }^{28}$ was developed and agreed upon by the study team, and the codes were then applied (by A.B.H. and T.J.S.), using qualitative data analysis software (ATLAS.ti version 6; Scientific Software Development $\mathrm{GmbH}$, Berlin). The content of each code was summarized and reviewed with the larger team, highlighting actionable findings. Analysis of both waves of interviews took place immediately following data collection, such that the midimplementation findings could be used to inform the implementation strategy to address barriers to implementation and to make minor adjustments to components of the toolkit (see below).

\section{Chart review}

To measure changes in clinician practices related to cancer family history documentation and referral for genetic consultation, we reviewed a random $10 \%$ sample of redacted progress notes created by each clinician for unique patients seen each month in the women's clinics during the preimplementation and implementation phases. During implementation, we characterized the progress notes according to whether the reminder was completed in the selected note, completed on a prior visit, or not completed in the selected note or any prior visits. If the reminder was completed during a prior visit to the women's clinics, we could not access the progress notes for that prior visit, and therefore, we could not assess which provider completed the reminder or the family history generated by the reminder. We could only assess whether the reminder had been completed previously. For each note selected, two research assistants abstracted and entered data into a database. The double-data entry served as a means for data quality assurance, with adjudication of any discrepant entries. Data abstracted included patient demographics (year of birth, age, race, ethnicity, sex); number and types of active medical problems; personal history of cancer, including age at diagnosis; family history of cancer, including presence, absence, or unknown cancer history for first-degree, maternal, and paternal second-degree and more distant relatives, and, if present, type of cancer and age at diagnosis; Jewish ancestry; prior genetic testing in the patient or family; and whether a genetic consult was requested.

\section{Tracking use of the reminder}

Clinician responses to the questions asked in the reminder created electronic data elements that populated the database supporting the GLA's EHR. ${ }^{29}$ Using these data elements, we generated monthly reports describing each patient with a completed reminder. The reports included data about patient demographics, clinical location, personal and family history (as described above), and whether a genetic consult was requested. 


\section{Tracking referral to genetics}

The clinical genetics service provided aggregate data to the research team about patients referred from the women's clinics during the implementation period, including whether the reminder was completed by the referring clinician, whether the genetic consult was completed, changes in family history and familial risk after genetic consultation, and uptake of genetic testing. The cancer family history was provided on the genetic consult request by the referring clinician, and if used, the data elements from the reminder were also included. The research team assessed the impact of the reminder by assessing the types of cancer noted, as well as assessing the familial risk level and features of HBOC and Lynch syndrome according to published criteria, ${ }^{30,31}$ at the time of referral and after completion of the consult.

\section{Statistical analyses}

We computed descriptive statistics to summarize patient and clinician information. We used $t$-tests to compare means of quantitative variables and $\chi^{2}$ analyses for homogeneity to compare the frequency distributions of categorical variables. Multivariate logistic regression was employed to assess associations between documentation of the cancer family history or use of the reminder and various predictor variables, including patient characteristics (age, race/ethnicity); number of active medical problems; presence of psychiatric diagnoses, substance abuse or other psychosocial issues (e.g., lack of housing, familial disruption); provider type (physician, nonphysician, or trainee); and clinic location. All statistical analyses were performed using STATA data analysis and statistical software version 12.0 (STATA, College Station, TX). To account for the potential clustering effect of patient results within clinician, the regression models incorporated this cluster adjustment in the analysis using a statistical function in STATA. This included the allowance for a variance-covariance matrix that incorporated a nonzero correlation structure in the data.

\section{Enrolled clinicians}

\section{RESULTS}

Seven of 10 clinicians (five physicians, one physician assistant, and one nurse practitioner) participated in the needs assessment survey and semistructured interviews. The same seven clinicians participated in the pre-post surveys and the interviews at 7 and 18 months during implementation. All were female, which is customary for staffing of the women's clinics. The clinicians had an average of 12 years (range 5-19 years) of experience in primary-care practice and 9.5 years (range 3-18 years) at the VA. One physician assistant was reassigned to another clinic after initiation of the study and neither she nor the eight patient records she created were included in the analyses.

\section{Clinician reactions to the toolkit}

After 7 months of implementation, we learned from the enrolled clinicians that certain toolkit components needed improvement, and we made changes accordingly. Specifically, the practice-feedback reports were difficult to understand due to the formatting; as a result, we imbedded graphics within the report text and color-coded the results to distinguish the clinician's results as compared with her peers in the clinic. We also learned that sending hard copies of these reports through interoffice mail was not ideal, and that e-mail was a preferred mode of delivery. With respect to the clinical reminder and corresponding patient questionnaire, we created two stem questions from one that had originally asked about personal history of polyps or cancer. The clinicians found it more straightforward to ask a separate question about personal history of colon polyps and another about personal history of cancer. We also changed the interval for updating a patient's cancer family history with the reminder from every 2 to every 3 years.

Overall, the clinicians valued the toolkit (see comments in Table 1). They reported increased confidence regarding recognition and referral of high-risk patients. Of the various toolkit components, the clinicians most valued the clinical reminder and lectures; the latter provided context for use of the reminder. The reminder was easy to use and generally took only a few minutes to complete. Clinicians also became more aware of the role of the clinical genetics service and appreciated the opportunity to make referrals, something none of them had done prior to toolkit implementation; all had referred at least one patient after implementation.

\section{Change in clinician knowledge and attitudes}

To assess change in clinician knowledge and attitudes, the needs assessment survey was administered to the seven enrolled clinicians before our toolkit was implemented and 18 months after implementation. The mean total correct responses increased from 59\% (range: $26-77 \%$ ) preimplementation to $73 \%$ (range 52-90\%) postimplementation, $P=0.04$. Change in knowledge was greatest for the topic of genetic testing, with the mean of correct responses increasing from 33\% (range 0-67\%) to $71 \%$ (range 33-100\%), $P=0.03$. Substantial knowledge gains were also seen for items relating to management of hereditary cancer, ethical issues, and recognition of hereditary cancer syndromes. Attitudes regarding relevance of cancer genetic topics to the clinicians' practice were generally similar pre- and postimplementation. Genetic testing had the lowest median pre- and postscores of 2 (somewhat relevant), whereas pre- and postscores of 4 (very relevant) were given to the topics of familial risk assessment, recognizing hereditary cancer syndromes, and management of hereditary cancer.

\section{Change in documentation of cancer family history}

Table 2 describes the characteristics of the patients whose progress notes were selected for review during the 6-month preimplementation phase and 18-month implementation phase and the providers who created these notes. There were no statistically significant differences in the patients' age, race, ethnicity, number of active medical problems, or clinic location for the records selected $(P>0.05$ in all cases). 
Table 2 Characteristics of patients whose progress notes were randomly selected for review

\begin{tabular}{|c|c|c|c|}
\hline & $\begin{array}{c}\text { Preimplemen- } \\
\text { tation phase, } \\
\%(n=139)\end{array}$ & $\begin{array}{l}\text { Implementa- } \\
\text { tion phase, }{ }^{b} \% \\
(n=677)\end{array}$ & $P$ value \\
\hline Age, years (mean, SD) & $48.2(15.3)$ & $49.2(14.2)$ & 0.43 \\
\hline \multicolumn{4}{|l|}{ Race/ethnicity (\%) } \\
\hline Caucasian & 30.9 & 36.8 & 0.51 \\
\hline African-American & 33.8 & 34.0 & \\
\hline Hispanic & 13.0 & 10.2 & \\
\hline Other $^{c}$ & 8.6 & 5.9 & \\
\hline Not recorded & 13.7 & 13.1 & \\
\hline \multicolumn{4}{|c|}{ Providers creating progress notes (\%) } \\
\hline Enrolled clinicians ${ }^{d}$ & 52.5 & 56.6 & 0.02 \\
\hline Non-enrolled clinicians ${ }^{e}$ & 20.9 & 26.4 & \\
\hline Trainees $^{\dagger}$ & 26.6 & 17.0 & \\
\hline $\begin{array}{l}\text { Number of active problems } \\
\text { (median, IQR) }\end{array}$ & $11(6.8)$ & $11(8.4)$ & 0.57 \\
\hline $\begin{array}{l}\text { Documentation of any cancer } \\
\text { family history (\%) }\end{array}$ & 26.6 & 36.3 & 0.03 \\
\hline $\begin{array}{l}\text { Documentation of a positive } \\
\text { cancer family history (\%) }\end{array}$ & 20.3 & 24.5 & 0.36 \\
\hline
\end{tabular}

All but three of the records were from female patients; the others were transgender male-to-female. Any documentation about cancer family history was defined as mention of the presence, absence, or an unknown history of any cancer in any relative. A positive cancer family history was defined as any mention of any relative with any type of cancer at any age.

$\mathrm{IQR}$, interquartile range.

aJuly through December 2009. ' A April 2010 through September 2011; 24 patients declined to complete the reminder with their clinician. Includes Asian, Native Hawaiian and Pacific Islander, American Indian, and Alaskan Native. 'Includes the enrolled physicians, physician assistant, and nurse practitioner who participated in the needs assessment surveys and semistructured interviews. elncludes two staff physicians in the women's clinics who did not participate in the needs assessment surveys or semistructured interviews. Includes medical students, residents, and fellows; most trainees were supervised by enrolled clinicians ( $92 \%$ preimplementation phase and $96 \%$ implementation phase). The majority (>90\%) of trainees were supervised by one of the enrolled clinicians.

Any documentation of cancer family history-including mention of the presence, absence, or an unknown history of any cancer in any relative-was found in $26.6 \%$ of the 139 progress notes selected during the 6-month preimplementation phase, and this documentation increased by almost $10 \%$ to $36.3 \%(P=0.03)$ in the 677 notes selected from the 18-month implementation phase (Table 2). Documentation of a "positive" cancer family history, that is, mention of any relative with any type of cancer at any age, increased by $4 \%$ from 20.3 to $24.5 \%$ $(P=0.36)$ (Table 2). The number of active medical problems was significantly associated with cancer family history documentation. For every 10 additional medical problems, the odds of documentation decreased by $34 \%$ (odds ratio $=0.66,95 \%$ confidence interval: 0.46-0.94). Patient age and race/ethnicity; clinician characteristics; clinic location; and presence of psychiatric diagnoses, substance abuse, or social issues were not associated with cancer family history documentation.

Use of the reminder doubled the likelihood of documentation of the cancer family history (odds ratio $=2.09 ; 95 \%$ confidence interval: 1.39-3.15) after adjusting for the predictor variables. Table 3 shows the frequencies of documentation according to use of the reminder. During the implementation phase, if the reminder was completed on the day the selected note was created, then $100 \%$ of the notes had documentation of any cancer family history and $67.2 \%$ had documentation of positive cancer family history, as compared with only 26.6 and $20.9 \%$ during preimplementation, respectively $(P<0.001)$. Documentation of cancer family history in the selected note was much less than preimplementation rates if the reminder had been completed on an earlier date, with 15.9 vs. $26.6 \%(P<0.001)$ of notes documenting any cancer family history and 9.1 vs. $20.3 \%(P<$ 0.001) of notes documenting a positive cancer family history (Table 3). When clinicians did not use the reminder, there were no differences in documentation of cancer family history as compared with preimplementation rates.

When there was any documentation of cancer family history, the information was more complete when the reminder was used as compared with preimplementation, including information about first- and second-degree relatives, more distant relatives, and lineage (Table 4). In records with a positive cancer family history, information important for risk assessment was more often documented when the reminder was used $(n=80)$ as compared with preimplementation $(n=29)$, including age at cancer diagnosis in first-degree ( 40.0 vs. $13.8 \% ; P<0.05)$ and second-degree ( 43.8 vs. $13.8 \% ; P<0.05$ ) relatives, and Jewish ancestry (95.0 vs. $0 ; P<0.05)$.

\section{Use of the reminder and referrals to clinical genetics}

The clinicians and trainees staffing the women's clinics saw 2,321 unique patients during the implementation phase (Figure 1). The reminder was completed for $55 \%$. Use of the reminder doubled the rate of referrals for genetic consultation from 4.1 to $9.6 \%, P<0.0001$. Clinicians were 1.4 times more likely to complete the reminder for African-American than Caucasian patients (odds ratio $=1.38 ; 95 \%$ confidence interval: $1.07-1.77$ ). Patient age, number of medical problems, psychiatric or social issues, clinician characteristics, and clinic location were not associated with completion of the reminder.

Review of the family history at the time of referral showed family histories of breast or breast-ovarian cancers were most prevalent and were documented at similar rates when the reminder was used $(67.5 \%, n=123)$ or not used $(69.8 \%, n=$ 43). However, there were significant differences in documentation of other types of cancer family history according to use of the reminder. When the reminder was used, more colorectal cancer was documented (17.1 vs. $2.3 \%$ ), which translated to increased documentation of Lynch-like pedigrees, defined as combinations of colorectal, endometrial, ovarian, and gastric/ upper gastrointestinal malignancy, and fewer ovarian cancer only (4.1 vs. $16.3 \%$ ) or endometrial cancer only (2.4 vs. $7.0 \%)$, pedigrees, $P=0.006$.

About $60 \%$ of the 168 patients referred for genetic consultation were scheduled and kept their appointment during the implementation phase irrespective of the use of the reminder by their clinician (Figure 1). The assessment of the familial risk often changed after a more comprehensive family history was 
Table 3 Documentation of cancer family history in randomly selected progress notes according to completion of the reminder during the implementation phase

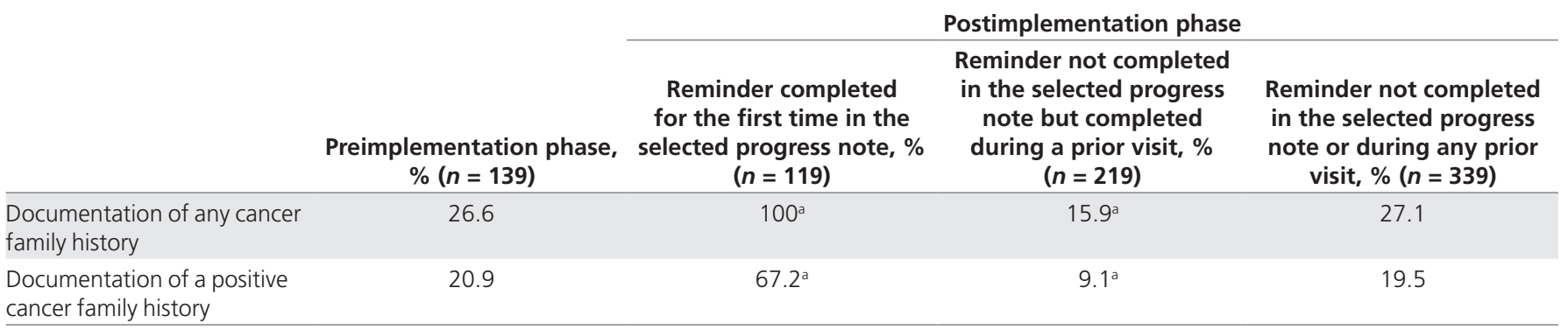

Any documentation about cancer family history was defined as mention of the presence, absence, or an unknown history of any cancer in any relative. A positive cancer family history was defined as any mention of any relative with any type of cancer at any age.

${ }^{a}$ Comparison with preimplementation rates showed significant differences, $P<0.001$.

Table 4 Documentation in randomly selected progress notes with any cancer family history according to completion of the reminder during the implementation phase

\begin{tabular}{|c|c|c|c|c|}
\hline \multirow[b]{2}{*}{ Documentation about: } & \multirow[b]{2}{*}{$\begin{array}{c}\text { Preimplementation } \\
\text { phase, } \%(n=37)\end{array}$} & \multicolumn{3}{|c|}{ Implementation phase } \\
\hline & & $\begin{array}{l}\text { Reminder completed } \\
\text { for the first time in the } \\
\text { selected progress note, \% } \\
(n=119)\end{array}$ & $\begin{array}{l}\text { Reminder not completed } \\
\text { in the selected progress } \\
\text { note but completed } \\
\text { during a prior visit, \% } \\
(n=35)\end{array}$ & $\begin{array}{c}\text { Reminder not completed } \\
\text { in the selected progress } \\
\text { note or during any prior } \\
\text { visit, } \%(n=92)\end{array}$ \\
\hline First-degree relatives & 43.2 & $98.3^{a}$ & $25.7^{a}$ & 51.1 \\
\hline Second-degree relatives & 35.1 & $99.2^{\mathrm{a}}$ & 31.4 & 16.3 \\
\hline Maternal & 8.1 & $96.6^{\mathrm{a}}$ & 14.3 & 13.0 \\
\hline Paternal & 5.4 & $96.6^{a}$ & 17.1 & 5.4 \\
\hline Lineage not specified & 21.6 & $1.7^{\mathrm{a}}$ & 11.4 & 3.3 \\
\hline More distant relatives & 5.4 & $13.4^{\mathrm{a}}$ & 2.9 & 6.5 \\
\hline
\end{tabular}

Any documentation about cancer family history was defined as mention of the presence, absence, or an unknown history of any cancer in any relative.

a $P<0.001$ for frequencies in implementation phase as compared with preimplementation phase.

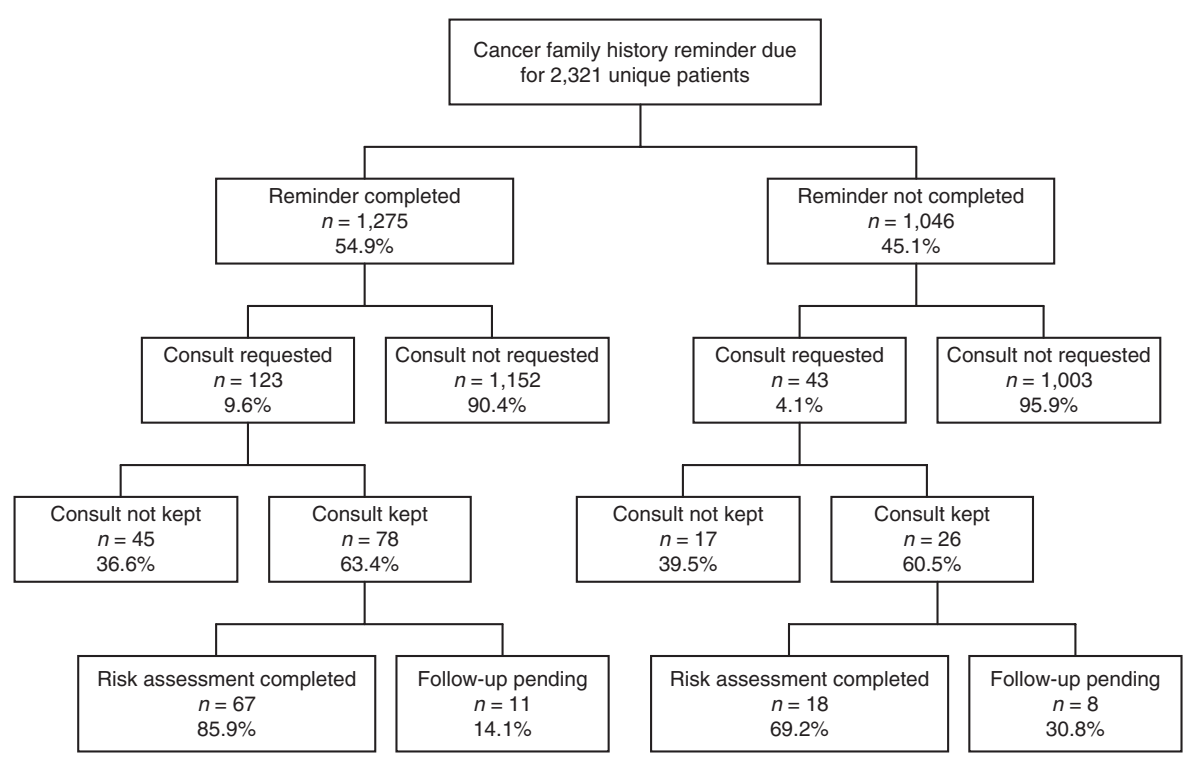

Figure 1 Utilization of genetic consultative services by women veterans according to completion of the cancer family history reminder in the electronic health record.

obtained during the genetic consultation; this change occurred significantly more often for the women for whom the reminder was not completed by their referring clinicians. Among the 26 patients without a completed reminder who were referred for genetic consultation, the assessed familial risk changed for $38.5 \%$ (five higher and five lower risk) as compared with only $18.0 \%$ ( 3 higher and 11 lower risk) for the 78 patients who had a completed reminder, $P=0.03$. The types of cancer reported as 
the reason for referral also changed after the genetic consultation; $50 \%$ of the 26 patients without a completed reminder had different and usually additional cancers reported in the family as compared with only $22 \%$ of the 78 who had a completed reminder, $P=0.006$.

After the initial genetic consultation, follow-up was sometimes necessary to gather more family history to assess familial risk and determine whether genetic testing was an option. The risk assessment process was completed more often for the patients who had been referred with a completed reminder as compared with those without a completed reminder (86 vs. $69 \%$, respectively; $P=0.078$ ). Of the 85 women who completed their genetic risk assessment, genetic testing was discussed with 21 (24.7\%) and ordered for 19 (two patients declined testing); this included $14(1.1 \%)$ of the 1,275 patients with a completed reminder and $7(0.7 \%)$ of the 1,046 patients without a completed reminder $(P=0.28)$.

\section{DISCUSSION}

With the goal of increasing access to genetic services, we developed, implemented, and evaluated an innovative multicomponent toolkit to facilitate collection and use of cancer family history by primary-care clinicians. We observed a significant increase in clinician knowledge regarding cancer genetics topics, and there was a significant increase in more complete cancer family history documentation in randomly selected progress notes during the toolkit implementation phase, which resulted in increased numbers of patients referred for genetic consultation. We also observed increased efficiencies related to collection, documentation, and use of the family history during the implementation phase of our study.

The reminder in the EHR was the most critical component of our toolkit, but other tools were important to its use and success. The reminder we created not only prompted the clinician to document cancer family history in a systematic way resulting in more complete documentation but required a decision regarding referral for genetic consultation to complete the reminder. Other studies have found improved clinical outcomes related to clinical decision support tools integrated within the EHR ${ }^{32}$ however, we believe this is the first successful example using a reminder for collection, documentation, and use of family history.

We also learned that the reminder improved efficiencies throughout the process of familial risk assessment. For patients referred to the genetics service, the more complete cancer family history obtained with the reminder by the primary-care clinicians reduced the need for genetics clinic follow-up during the implementation phase, thereby helping to maximize the capacity of the genetics service. We also observed that use of the reminder resulted in a significant reduction in cancer family history documentation by primary-care clinicians on subsequent clinic visits. We see this reduction as an increased efficiency and believe it was due to the clinicians' reliance on the reminder to trigger questioning; if the reminder was completed, then there was no perceived need to question patients about cancer family history. The appropriate interval for systematically asking patients about cancer family history has not been determined. ${ }^{33}$ We set our interval at 3 years based on feedback from the clinicians in the women's clinics.

Patient demographic characteristics were not associated with cancer family history documentation. This finding is different from studies that have found reduced rates of cancer family history documentation ${ }^{34}$ and genetic counseling ${ }^{35}$ for nonwhite patients that may underlie the racial disparities observed in uptake of genetic testing for HBOC. ${ }^{15,36}$ The number of medical problems was significantly related to documentation of the cancer family history, suggesting that time to discuss family history may have been limited for patients with multiple active medical problems, or clinicians may have perceived collection and documentation of cancer family history as less relevant for these patients. However, we did not find that the number of active medical problems was associated with use of the reminder. The only patient characteristic associated with use of the reminder was race. African-American patients were significantly more likely to have a completed reminder than Caucasian patients. These differences in patient characteristics related to cancer family history documentation and use of the reminder deserve further study.

There are several limitations of this study that deserve mention. This was a pilot study in primary-care clinics with only female clinicians and female patients at one large VA facility; therefore, applicability of the findings to other settings, clinicians, and patients is unknown. We selected this clinical setting because the increased cancer risks associated with HBOC and Lynch syndrome are highly relevant to female patients. Furthermore, we chose primary care because partnerships between primary-care and genetics professionals are important to accessibility of genetic services. ${ }^{37}$ Our methods of data collection (limited to one progress note from the entire record and tracking use of the reminder) are sufficiently different from other reports of cancer family history documentation such that a comparison of frequency of documentation cannot be made. ${ }^{34,38}$ The pre/postdesign without a control group could not account for temporal trends that might have influenced the cancer family history documentation, but we were able to compare outcomes for those patients referred for genetic consultation for whom a reminder was completed versus not completed.

In summary, our toolkit increased the frequency and improved the quality of the cancer family history documented by primary-care clinicians; increased recognition of high-risk patients, which is critical for delivery of risk-appropriate preventive care; and increased the numbers of appropriate referrals for genetic consultation. The cancer family history reminder was an innovative feature of the toolkit that leveraged the clinical decision support capabilities of the VA's EHR. The reminder reinforced learning at the point of care and increased access to clinical genetic services. It also increased efficiencies in the system regarding cancer family history documentation and 
genetic consultation. Based on the positive findings from this initial study, subsequent studies are needed to evaluate the toolkit in a larger and more diverse sample of settings in VA and non-VA facilities, and using a stronger randomized design with clinical outcome measures included.

\section{SUPPLEMENTARY MATERIAL}

Supplementary material is linked to the online version of the paper at http://www.nature.com/gim

\section{ACKNOWLEDGMENTS}

This publication was supported by Cooperative Agreement No. 1U38GD000047 from the Centers for Disease Control and Prevention. Its contents are solely the responsibility of the authors and do not necessarily represent the official views of the Centers for Disease Control and Prevention. We thank Muin Khoury for his review of the manuscript (he received no compensation), Lisa V. Rubenstein for her input to the study design and review of implementation activities, Shannon Rhodes for data management and preliminary analyses, and Austin Jones for his contributions to data entry and quality assurance. Rubenstein, Rhodes, and Jones provided these services in their respective roles as employees at the VA Greater Los Angeles Healthcare System.

\section{DISCLOSURE}

At the time of the study, A.B.H. was an investigator with the Implementation Research Institute, at the George Warren Brown School of Social Work, Washington University, St. Louis, MO, through an award from the National Institute of Mental Health (R25 MH080916-01A2) and VA HSR\&D QUERI. E.M.Y. was supported by a VA HSR\&D Senior Research Career Scientist Award (RCS \#05195). M.T.S. had full access to all the data in the study and takes responsibility for the integrity of the data and the accuracy of the data analysis. The authors declare no conflict of interest.

\section{REFERENCES}

1. National Comprehensive Cancer Network. Clinical Practice Guidelines in Oncology. Genetic/Familial High-Risk Assessment: Breast and Ovarian. Version I.2011 7 April 2011. http://www.nccn.org/professionals. Accessed 20 November 2012.

2. National Comprehensive Cancer Network. Clinical Practice Guidelines in Oncology. Colorectal cancer screening. Version 2.2011, 22 October 2010. http://www.nccn.org/professionals. Accessed 20 November 2012.

3. Sardanelli F, Podo F, Santoro F, et al.; High Breast Cancer Risk Italian 1 (HIBCRIT-1) Study. Multicenter surveillance of women at high genetic breast cancer risk using mammography, ultrasonography, and contrast-enhanced magnetic resonance imaging (the high breast cancer risk Italian 1 study): final results. Invest Radio/ 2011;46:94-105.

4. Huang M, Sun C, Boyd-Rogers S, et al. Prospective study of combined colon and endometrial cancer screening in women with lynch syndrome: a patientcentered approach. J Oncol Pract 2011;7:43-47.

5. Rebbeck TR, Lynch HT, Neuhausen SL, et al.; Prevention and Observation of Surgical End Points Study Group. Prophylactic oophorectomy in carriers of BRCA1 or BRCA2 mutations. N Engl J Med 2002;346:1616-1622.

6. Rebbeck TR, Friebel T, Lynch HT, et al. Bilateral prophylactic mastectomy reduces breast cancer risk in BRCA1 and BRCA2 mutation carriers: the PROSE Study Group. J Clin Oncol 2004;22:1055-1062.

7. Eisen A, Lubinski J, Klijn J, et al. Breast cancer risk following bilateral oophorectomy in BRCA1 and BRCA2 mutation carriers: an international casecontrol study. J Clin Oncol 2005;23:7491-7496.
8. Järvinen $\mathrm{HJ}$, Aarnio M, Mustonen $\mathrm{H}$, et al. Controlled 15-year trial on screening for colorectal cancer in families with hereditary nonpolyposis colorectal cancer. Gastroenterology 2000;118:829-834.

9. Schmeler KM, Lynch $\mathrm{HT}$, Chen LM, et al. Prophylactic surgery to reduce the risk of gynecologic cancers in the Lynch syndrome. N Engl J Med 2006;354:261269.

10. Narod SA, Brunet JS, Ghadirian P, et al.; Hereditary Breast Cancer Clinical Study Group. Tamoxifen and risk of contralateral breast cancer in BRCA1 and BRCA2 mutation carriers: a case-control study. Hereditary Breast Cancer Clinical Study Group. Lancet 2000;356:1876-1881.

11. Chan AT, Lippman SM. Aspirin and colorectal cancer prevention in Lynch syndrome. Lancet 2011;378:2051-2052.

12. U.S. Preventive Services Task Force. Genetic risk assessment and BRCA mutation testing for breast and ovarian cancer susceptibility: recommendation statement. Ann Intern Med 2005;143:355-361.

13. Evaluation of Genomic Applications in Practice and Prevention (EGAPP) Working Group. Recommendations from the EGAPP Working Group: genetic testing strategies in newly diagnosed individuals with colorectal cancer aimed at reducing morbidity and mortality from Lynch syndrome in relatives. Genet Med 2009;11:35-41.

14. Bellcross CA, Kolor K, Goddard KA, Coates RJ, Reyes M, Khoury MJ. Awareness and utilization of BRCA1/2 testing among U.S. primary care physicians. Am J Prev Med 2011:40:61-66.

15. Baer HJ, Brawarsky P, Murray MF, Haas JS. Familial risk of cancer and knowledge and use of genetic testing. J Gen Intern Med 2010;25:717-724.

16. Trivers KF, Baldwin LM, Miller JW, et al. Reported referral for genetic counseling or BRCA 1/2 testing among United States physicians: a vignette-based study. Cancer 2011;117:5334-5343.

17. Scheuner MT, Sieverding P, Shekelle PG. Delivery of genomic medicine for common chronic adult diseases: a systematic review. JAMA 2008;299:1320-1334.

18. Burke W, Culver J, Pinsky L, et al. Genetic assessment of breast cancer risk in primary care practice. Am J Med Genet A 2009;149A:349-356.

19. Brierley $\mathrm{KL}$, Campfield $\mathrm{D}$, Ducaine $\mathrm{W}$, et al. Errors in delivery of cancer genetics services: implications for practice. Conn Med 2010;74:413-423.

20. United Healthcare Center for Health Reform \& Modernization. Personalized medicine: Trends and prospects for the new science of genetic testing and molecular diagnostics. Working Paper 7 March 2012, p 23. http://www. unitedhealthgroup.com/hrm/UNH_WorkingPaper7.pdf. Accessed 6 May 2012.

21. Curran GM, Mukherjee S, Allee E, Owen RR. A process for developing an implementation intervention: QUERI Series. Implement Sci 2008;3:17.

22. Mazmanian PE, Davis DA. Continuing medical education and the physician as a learner: guide to the evidence. JAMA 2002;288:1057-1060.

23. Oxman AD, Thomson MA, Davis DA, Haynes RB. No magic bullets: a systematic review of 102 trials of interventions to improve professional practice. CMAJ 1995;153:1423-1431

24. Mansouri M, Lockyer J. A meta-analysis of continuing medical education effectiveness. J Contin Educ Health Prof 2007;27:6-15.

25. Khoury MJ, Coates RJ, Fennell ML, et al. Multilevel research and the challenges of implementing genomic medicine. J Natl Cancer Inst Monographs 2012;2012:112-120.

26. Yano EM, Washington DL, Goldzweig C, Caffrey C, Turner C. The organization and delivery of women's health care in Department of Veterans Affairs Medical Center. Womens Health Issues 2003:13:55-61.

27. Yano EM, Goldzweig C, Canelo I, Washington DL. Diffusion of innovation in women's health care delivery: the Department of Veterans Affairs' adoption of women's health clinics. Womens Health Issues 2006;16:226-235.

28. Richards T, Richards L. Using hierarchical categories in qualitative data analysis. In: Kelly U (ed). Computer-Aided Qualitative Data Analysis. Theory, Methods, and Practice. Sage: London, 1995:80-95.

29. Evans DC, Nichol WP, Perlin JB. Effect of the implementation of an enterprisewide Electronic Health Record on productivity in the Veterans Health Administration. Health Econ Policy Law 2006;1(Pt 2):163-169.

30. Scheuner MT, Wang SJ, Raffel LJ, Larabell SK, Rotter JI. Family history: a comprehensive genetic risk assessment method for the chronic conditions of adulthood. Am J Med Genet 1997:71:315-324.

31. Scheuner MT, McNeel TS, Freedman AN. Population prevalence of familial cancer and common hereditary cancer syndromes. The 2005 California Health Interview Survey. Genet Med 2010;12:726-735.

32. Kawamoto K, Houlihan CA, Balas EA, Lobach DF. Improving clinical practice using clinical decision support systems: a systematic review of trials to identify features critical to success. BMJ 2005;330:765. 
33. Qureshi N, Carroll JC, Wilson B, et al. The current state of cancer family history collection tools in primary care: a systematic review. Genet Med 2009;11:495-506.

34. Murff HJ, Byrne D, Haas JS, Puopolo AL, Brennan TA. Race and family history assessment for breast cancer. J Gen Intern Med 2005;20:75-80.

35. Armstrong K, Micco E, Carney A, Stopfer J, Putt M. Racial differences in the use of BRCA1/2 testing among women with a family history of breast or ovarian cancer. JAMA 2005;293:1729-1736.
36. Levy DE, Byfield SD, Comstock CB, et al. Underutilization of BRCA1/2 testing to guide breast cancer treatment: black and Hispanic women particularly at risk. Genet Med 2011:13:349-355.

37. Feero WG. Genetics of common disease: a primary care priority aligned with a teachable moment? Genet Med 2008:10:81-82.

38. Medalie JH, Zyzanski SJ, Langa D, Stange KC. The family in family practice: is it a reality? J Fam Pract 1998;46:390-396. 